\title{
An Econometric Analysis of the Impact of the RDP on the Demand for Construction Materials in South Africa
}

\section{Charles C Okeahalam}

Donald Gordon Professor, Graduate School of Business, University of the Witwatersrand

\section{ABSTRACT}

The Reconstruction and Development Programme (RDP) is an attempt by the South African government to redress the imbalances of apartheid. It has many facets. One of these involves the provision and distribution of infrastructure to citizens who hitherto have been neglected. This calls for significant construction effort particularly for housing, water, roads and other social construction. This will require efficient production, and allocation of resources to ensure that there is adequate supply of materials to meet the likely increase in demand. This paper examines the expected demand for construction materials, assesses the supply capacity of South African suppliers of construction materials, and develops an econometric model which can be used to evaluate the impact that growth of the internal construction activity will have on construction industry suppliers.

JEL O11

\section{INTRODUCTION}

The role of construction as part of Keynesian economic policy has been debated, by for example Coates and Hillard (1987) and Fishlow (1995). Some, such as Easterley and Vierra da Cunha (1994) and Tanzi (1996), see specific industrial sector focus, unwarranted by potential for positive expected financial returns, to be a distortion of incentives and thus a form of fiscal laxity. Accordingly, they consider pump-priming (greater expenditure by government on public works on construction as a method of stimulating economic growth) to be inefficient; indeed detrimental, to long term growth.

Different conditions face each of the Southern African countries in terms of resources, population, economic and technological levels. The objective of this paper is to provide an analysis of recent trends and patterns within the 
construction industry of the Southern Africa region and then develop a framework to conduct an econometric analysis of the South Africa construction material demand-supply position. Section 2 provides an analysis and evaluation of salient trends, in section 3 we estimate an econometric model to test the data, in section 4 we present the findings of the econometric exercise, section 5 gives some methodological points with which to validate the results, section 6 contains conclusions and section 7 provides recommendations, managerial implications and areas for future research.

\section{REVIEW OF TRENDS IN THE SOUTHERN AFRICA CONSTRUCTION SECTOR}

In what follows here, we discuss the main trends in the data to provide an overview to the reader and to describe the data used in the econometric model which follows in section 3. The data set used is based on information for the four-year inclusive period of 1991 to 1994 and is derived primarily from desk top and library search from a variety of publications, including the Business Construction Review (1992, 1993 and 1994) and publications of the Southern African Research Strategy Consulting Unit (SARSCU) - notably, The Market for Building Materials (1996).

As noted in Gouden, Merrifield, Amod and Nkosi (1996) it is inevitable that effects of war damage and insufficient delivery of transport infrastructure will influence the rate of inflation in the regional construction industry and this varies greatly, as can be seen in Table 1 below. Furthermore, Table 2 shows the different annual rates of change in planned residential investment in the southern Africa region. This shows that Botswana which has experienced significant annual rates of economic growth has the highest rate $(110.5 \%)$ while Tanzania has the lowest $(6.9 \%)$. In Table 3, again it can be seen that, with regard to the non-residential sector, Namibia has the highest $(39.5 \%)$ and Mozambique the lowest rate $(6 \%)$. The size and growth of the construction industry of countries in the Southern Africa region thus differ and the extent to which they have penetrated each others' construction markets and industries will also differ. 
Table 1 Average construction industry inflation rate (\%) in southern African (SADC) countries

\begin{tabular}{|l|r|r|r|r|r|}
\hline COUNTRY & 1991 & 1992 & 1993 & 1994 & MEAN \\
\hline Angola & 1185.4 & 1011.9 & 1617.1 & 1738 & 1388.1 \\
\hline Botswana & 12.0 & 11.6 & 11.1 & 10.9 & 11.4 \\
\hline Lesotho & 15.2 & 15.5 & 15.1 & 15.6 & 15.4 \\
\hline Malawi & 28.8 & 25.1 & 24.6 & 19.8 & 24.6 \\
\hline Mozambique & 497.9 & 454.5 & 404.3 & 343.6 & 425 \\
\hline Namibia & 12.1 & 9.2 & 8.6 & 8.9 & 9.6 \\
\hline South Africa & 14.4 & 14.6 & 14.5 & 14.7 & 14.6 \\
\hline Swaziland & 14.7 & 15.0 & 14.9 & 15.1 & 14.9 \\
\hline Tanzania & 25.9 & 25.2 & 24.4 & 22.0 & 24.4 \\
\hline Zambia & 29.1 & 27.6 & 27.9 & 28.7 & 28.3 \\
\hline Zimbabwe & 19.0 & 18.7 & 18.4 & 17.2 & 18.3 \\
\hline
\end{tabular}

Sources:Statistical Year Book, United Nations, 1994 Construction Industry Study, Botswana Technology Centre, 1992 Southern African Research Centre, Harare, Zimbabwe. Economic Research Bureau, University of Dar es Salaam, 1991; Central Statistical Office, Mbabane, Swaziland; The Economic Intelligence Unit Ltd, 1994; Business and Construction Review, June 1993; The Central Bank of Swaziland, 1993; Bank of Tanzania Annual Report, 1992.

Table 2 Southern African construction industry indicators, annual rate (\%) of change for residential buildings approved plan/investment

\begin{tabular}{|l|r|r|r|r|r|}
\hline COUNTRY & \multicolumn{1}{|l|}{1991} & \multicolumn{1}{l|}{1992} & \multicolumn{1}{l|}{1993} & \multicolumn{1}{l|}{1994} & MEAN \\
\hline Angola & 2.3 & 2.6 & 4.5 & 4.8 & 3.5 \\
\hline Botswana & 50.7 & 30.1 & 20.8 & 8.9 & 27.6 \\
\hline Lesotho & 3.4 & 4.3 & 4.4 & 3.6 & 4.0 \\
\hline Malawi & 2.1 & 3.6 & 3.3 & 2.9 & 2.9 \\
\hline Mozambique & 1.8 & 2.7 & 2.2 & 2.9 & 2.4 \\
\hline
\end{tabular}


Table 2 continued

\begin{tabular}{|l|r|r|r|r|r|}
\hline COUNTRY & \multicolumn{1}{|l|}{1991} & \multicolumn{1}{l|}{1992} & \multicolumn{1}{l|}{1993} & \multicolumn{1}{l|}{1994} & \multicolumn{1}{l|}{ MEAN } \\
\hline Namibia & 9.8 & 8.7 & 7.1 & 7.8 & 8.4 \\
\hline South Africa & 4.5 & 10.3 & 14.7 & 21.2 & 12.7 \\
\hline Swaziland & 4.5 & 6.1 & 5.9 & 4.2 & 5.2 \\
\hline Tanzania & 2.0 & 1.0 & 1.5 & 2.4 & 1.7 \\
\hline Zambia & 2.3 & 2.6 & 2.0 & 1.8 & 2.2 \\
\hline Zimbabwe & 13.2 & 13.8 & 13.1 & 12.9 & 13.1 \\
\hline
\end{tabular}

Sources:CSIR Pretoria, personal communication division of information services (INFORTEK) Construction Industry Study, Botswana Technology Center, 1992; Bureau of Economic Research, University of Stellenbosch, Building and Construction Business and Construction Review, 1996; Development and Cooperation, 1990; Central Bank of Swaziland, 1993.

Table 3 Southern African construction industry indicators, annual rate of change for non- residential buildings approved plan/ investment

\begin{tabular}{|l|c|c|c|c|c|}
\hline COUNTRY & 1991 & 1992 & 1993 & 1994 & MEAN \\
\hline Angola & 3.7 & 4.1 & 2.1 & 4.2 & 3.5 \\
\hline Botswana & 8.2 & 7.8 & 7.6 & 7.2 & 7.7 \\
\hline Lesotho & 24.1 & 2.6 & 3.7 & 3.0 & 8.4 \\
\hline Malawi & 2.9 & 1.6 & 2.7 & 1.7 & 2.2 \\
\hline Mozambique & 1.6 & 1.4 & 2.0 & 1.0 & 1.5 \\
\hline Namibia & 9.6 & 6.4 & 12.3 & 11.2 & 9.9 \\
\hline South Africa & 10 & 15 & 20 & 23 & 17.0 \\
\hline Swaziland & 5.2 & 3.6 & 5.0 & 4.5 & 4.6 \\
\hline Tanzania & 4.9 & 3.5 & 2.6 & 2.1 & 3.3 \\
\hline Zambia & 3.7 & 4.9 & 3.3 & 2.6 & 3.6 \\
\hline Zimbabwe & 6.9 & 7.8 & 6.3 & 5.0 & 6.5 \\
\hline
\end{tabular}


Sources: Business and Construction Review, 1992-93Ministry of Works, Transport and Communications, Botswana

Quarterly Economic and Statistical Review, Zimbabwe.

Although not shown here, the data set makes it possible to observe that the demand for South Africa bricks is highest in South Africa itself. We can also observe that the largest regional importer of bricks which are manufactured in South Africa is Botswana. The data moreover suggests that Botswana as the major importer of bricks is followed by Namibia, Swaziland and Lesotho. We suggest that the prime reason for this is geographical proximity.

There also appears to be a significant amount of horizontal and vertical integration between South African construction companies and construction material manufacturers in Namibia, Lesotho, and Swaziland.

Table 4 Percentage of GDP allocated to the construction in SADC countries in 1994

\begin{tabular}{|l|c|}
\hline COUNTRY & PERCENTAGE \\
\hline Angola & 12.1 \\
\hline Botswana & 33.8 \\
\hline Lesotho & 6.5 \\
\hline Malawi & 4.8 \\
\hline Mozambique & 10.6 \\
\hline Namibia & 7.1 \\
\hline South Africa & 30.2 \\
\hline Swaziland & 6.9 \\
\hline Tanzania & 5.2 \\
\hline Zambia & 5.0 \\
\hline Zimbabwe & 5.1 \\
\hline
\end{tabular}

Sources: Southern African Research Centre, Harare, Zimbabwe

Construction Industry Study, Botswana Technology Centre, 1992

Building Research Strategy Consulting Uniq Pty), Ltd, "The market for materials 1990-95'

Quarterly Economic and Statistical Review, Zimbabwe, 1992

World Bank Report, 1994. 
Table 4 indicates the role which the construction industry plays in the GDP of Southern Africa countries. It would also appear that countries which until recently were involved in war and conflict, notably Angola and Mozambique, are currently allocating a high proportion of their GDP to construction. However, the actual size of this growth for Angola and Mozambique is still lower in monetary terms than that of Botswana, and of course South Africa. The latter in particular, has socio-economic and political reasons for allocating a high proportion of its GDP to this industry sector.

The data trends suggest that given the peaceful conditions which now prevail in most of the region, economic growth is likely to be more buoyant and the region-wide demand for South Africa materials should increase accordingly. This is primarily because of the significant technological advantages which it would appear South Africa has over its regional neighbours. Now, given the construction sector demand-impact which will be generated by the Reconstruction and Development Programme (RDP), ${ }^{1}$ neighbouring countries may experience either supply backlogs in quantity and time, and/or, they may experience price inflation depending on the extent to which the sector becomes overheated.

\section{METHODOLOGY - SPECIFICATION AND TEST OF AN ECONOMETRIC MODEL}

To validate the above view, in this section we use econometric methods to test the demand for South African construction materials, and the impact that the growth of internal (SA based) construction activity will have on this demand.

The demand for construction materials is a derived demand, arising from the commissioning of construction projects - projects which will use materials as part of the construction process. Here we develop an econometric framework in which the derived demand level for construction materials is made conditional on demand for construction projects. The largest catalyst of the demand for construction projects and therefore materials, is likely to be the RDP..

It is clear that the actual demand/supply structure of materials will vary as we near finite levels, however the principal economic trends, even if different in impact, applies to different types of materials. Accordingly we proceed in a generic framework to establish likelihood relationships which in principle should be applicable to all materials. The model is: 


$$
Y_{i t}=\Sigma U C M C_{j t} X_{1} \alpha+G D P_{j t} X_{2}+R D P_{j t} X_{3} \beta+E T L_{j t} X_{4}+\theta+\epsilon_{i t}
$$

where

$Y_{j i t}=$ is the dependent variable and the total demand for construction materials $j$ in period $t$ for construction project $i$;

$U C M C_{j i r} X_{i}=$ unit construction material consumption of material $j$ in period $t$ by construction project $i$;

$\alpha \quad=$ vector of parameters associated with $U C M C_{j i t} X_{l}$;

$G D P X_{3} \quad=$ country average GDP growth rate;

D. $R D P X_{3}=$ a binary dummy variable ${ }^{2}$ for a vector of RDP independent construction project commission rate variables;

$\beta \quad=$ vector of parameters associated with $R D P X_{3}$,

$E T L X_{4}=$ economic trade link variables;

$\theta=$ vector of parameters ${ }^{4}$ of economic trade links which are correlated with neighbouring country demand for SA country materials;

$E_{i t} \quad=$ error term for construction project $i$ in period $t$.

The term $R D P X_{3}$ accounts for the range of possible types of construction projects, housing, roads, bridges, dams. For our purpose the distribution of the $U C M C_{i t}$ associated with these specific projects is of less interest than the aggregate level.

A pure conditional-demand approach approximates the terms $U C M C_{\text {it }}$ via variables related to the type of construction project under consideration. Specification can take a linear form and be simplified by using the financial value of the construction project as a proxy for the use of construction materials; linearly the higher the value of the project the more material is used. However, there is a problem with this specification in that different projects use materials at a different rate and accordingly, the demand for construction materials is not fully correlated nor monotonic in functional form.

An engineering-econometric approach would condition a $U C M C$ specific type of project and the underlying technology to be used. Thus the structure of the estimated equation would be best emphasised by including all the relevant construction engineering data available. Using this latter approach, to apply the model empirically it would be necessary to focus on the specific end uses of construction materials at the rate that they differ for different types of construction. This would elicit cross-sectional as well as regional/country variations. However, in the case of roads for example, if a regional road construction plan exists it would be possible to enter calibrations based on this plan into the model. For housing we could, given the RDP, subtract the term from the left hand side of the equation. If the values are measured with error, 
this approach may reduce the parameter estimates of $\beta^{i}$ but should not bias the estimates, if the measurement errors are uncorrelated with the right hand side variables.

The estimation of the model has to take cognisance of the cross-sectional and time-series properties of the data and attempt, in particular, to exploit the UCMC $j$ response rates over time. We also have to assume homoscedasticity of disturbances for the construction period of every $i$.

Given differences in each $i$, the paucity of the time-series data available and the increase in empty cells that arise from cross-sectional disaggregation, this would be a reasonable assumption. ${ }^{6}$ Even if we assume that the cross-section and time series construction material demand data are independent for each $i$, it is still possible to assess individual project construction material demand over time. To do this we need to assume that the disturbances in each project material demand behaviour structure are equi-correlated over time and given the current vintage of technology are time-invariant. Such a situation may arise from unobservable but universally applicable or acceptable standard construction project characteristics such as, for roads, the number of metres per tonne of bitumen, or in the case of house construction, the number of cement bags required to produce bricks. The calculus then simply becomes arithmetic, as demand is then a function of scale. Alternatively, given the RDP, we can argue with some persuasion that disturbances have an auto-regressive structure in which $E\left(\epsilon_{i r} \in i s\right)=\rho^{i .5}$.

4 FINDINGS - RESULTS OF THE MODEL ESTIMATES.

Table 5 Model Estimates

\begin{tabular}{|l|c|c|}
\hline & Estimate & Standard Error (SE) \\
\hline $\mathrm{UCMC}_{\text {iit }} \mathrm{X}_{1}$ & 0.714 & $(0.023)$ \\
\hline $\mathrm{GDPX}_{2}$ & 0.391 & $(0.011)$ \\
\hline $\mathrm{D}-\mathrm{RDPX3}$ & & \\
D RDPX3-O & 0.54 & $(0.017)$ \\
$\mathrm{D} \mathrm{RDPX}^{-1}$ & 0.23 & $(0.004$ \\
\hline ETLX $_{4}$ & 0.29 & $(0.316)$ \\
\hline Validation: $^{6}$ & & $\mathrm{Df} \mathrm{L}^{*}(0)=183.7$ \\
\hline Log-likelihood $(0)$ & $\mathrm{L}^{*}(0)=-512242$ & $\mathrm{Df} \mathrm{L}^{*}(\beta)=141.4$ \\
\hline Log-likelihood $(\beta)$ & $\mathrm{L}^{*}(\beta)=-366125$ & \\
\hline $\bar{p}^{2}=$ & 0.322 & \\
\hline
\end{tabular}


To gain further information in support of the data in the tables, we have calibrated, estimated, and validated the above model. There are some empirical problems which we should briefly touch on before the provision of results. Given that we wish to understand what the impact that $S A$ demand will have on the $S A$ construction material supply-demand position, we have disaggregated the data and removed all non-SA demand. We have also divided each annual entry into quarterly entries to be able to have sufficient data points to fit the number of explanatory variable parameters. While this diverges from reality in that the level of demand for construction material is unlikely to be uniform for each quarter of the year, it allows for a better fit of the model and does not distort the aggregate numbers since the quarterly entries are obviously a function of the yearly entries.

We estimated the above model equation using the maximum-likelihood technique. ${ }^{7}$ As would be expected the estimated coefficient for $U C M C_{j i t}$ is extremely significant. This is to be expected, given the way this explanatory variable is specified and the strong correlation this variable has relative to $Y_{j i t}$. Although the parameter estimate is significant, the relationship is not univariate. The GDPX, is also significant, suggesting that the level of GDP in the years for which we have time-series data has a positive influence on the demand for construction materials.

The coefficient for $D-R D P X_{3}-O$ is significant, suggesting that the RDP will have an impact even if the trend in construction demand is constant at the underlying rate. The estimate for $D-R D P X_{3}-1$ is smaller than that for 0 but significant, suggesting that the $6 \%$ stimulus of the RDP will also have an impact on the demand for construction materials. Finally, we tried to test the hypothesis that the level of economic trade links that exist between SA and each of her neighbours, measured by data from the current account trade balance tables, would have some discernable impact on the demand for construction materials. However, while the coefficient value supports this view, it is not statistically significant and as such is a null hypothesis. 


\section{VALIDATION AND OTHER METHODOLOGICAL ISSUES}

Data has been collected from a variety of sources which are listed in the references. The methodology has involved evaluation of data count, such that with the observed data we are fairly sure that we have not double counted and that the variety of sources used does not bias the overall results. This is the usual methodology that is used with some form of asymptotic estimator to validate combined cross-section and time-series (panel) data. This is particularly so with regard to some construction materials where, as we disaggregated further, the number of empty cells increased.

I do feel that for further investigation and as the analysis becomes more detailed, there is a need to employ some form of simple random sampling, stratified sampling or exhaustive sampling to validate the overall statistical consistency. To gain further statistical confidence information on the significance of RSA firm demand of SA materials, a two-step estimation process would then isolate the significant variables of equation 1 , and this could then be re-estimated by using $X_{1}$ and $X_{3}$ in a reduced-form equation. We however have insufficient data on SA firm involvement and are therefore unable to estimate the reduced form. However this should be pursued in later work.

\section{CONCLUSIONS}

It is quite clear that the RSA construction sector is the major determinant of the derived-demand level for RSA construction materials. We also see that a very high proportion of RSA GDP is geared to construction and allied sectors. We believe that while the RDP is undoubtedly going to stimulate the level of internal demand for construction materials, given macroeconomic limitations, of its own accord, it is not going to be capable of creating the level of demand pull, to present supply capacity problems and industrial construction material inflation. " The regional impact of RSA construction material supply sector is most readily felt in Botswana, Namibia and latently in Mozambique. However, the building boom that drove the Botswana demand is over. Furthermore it is clear that the further we move from RSA, the less significant is its role as a supplier of construction materials to Southern Africa. There is significant scope for development in this regard. The corollary is also worthwhile noting, in that there has been little or no inroad into the RSA market by her regional neighbours.

The econometric analysis suggests that there is a fairly strong relationship between the unit material consumption rate for construction projects, that the RSA economic growth rate is positively related to domestic demand for 
construction materials, and that the RDP, whether measured at the underlying rate or a multiplier of $1.06 / 1$ also has a positive impact on internal demand for construction materials.

\section{RECOMMENDATIONS, MANAGERIAL IMPLICATIONS, AND FUTURE RESEARCH}

An interesting managerial implication of this is that SADC governments need to find ways in which regional construction business suppliers can enter the expanding SA construction supply market, and effectively manage strategic partnerships in the vertical or horizontal supply chain which develops. See Forrest (1992) and Fellows and Langford (1993).

The primary strategic managerial implication is that managers in the Southern Africa construction material supplies industries need to closely examine the possibility of joint ventures to share market revenues. The joint ventures need to be designed in such a way that while they are profitable, in that they yield adequate returns on the capital employed, they do not lead to political discord and trade protectionism, as charges are made of attempting to dominate local, national or regional markets. Accordingly, assessing the long term impact which such joint ventures may have on demand and supply patterns is an area of research, which in the future, should be further developed.

\section{END NOTES}

1 The RDP is the blue print for economic and social development which was developed by the African National Congress (ANC) led majority government in 1994. There is a level of construction activity which would exist without the impact of the RDP. Accordingly we need to ascertain the level of pre-RDP construction activity level and subtract this from the RDP construction activity level. We envisage the RDP to be a major catalyst of the 'growth of the internal construction activity' that is referred to in brief and accordingly $I$ devote attention to its role the econometric model developed herein.

2 This dummy variable takes the value 0 for non-RDP related growth in the demand for construction materials, i.e. the underlying pre-RDP growth rate and 1 for a factor of $(+6 \%)$ which is added to the underlying rate and is determined by the RDP induced growth in demand for construction materials. This factor is equivalent to RDP construction sector rate minus non-RDP underlying construction sector growth rate. We have calibrated this aspect of the model with $6 \%$. It is based on the government's blue- 
print macroeconomic annual growth forecast of 1996, which has unfortunately proved ambitious, but was the best information available at the time.

3 This variable can be established by examining the degree of openness which each country has with the RSA via protocols, agreements and tariffs apart from the general SADC positions on such issues. It can also be calibrated as the actual observed level of trade between the two countries, and is the method we use when we introduce this model in the estimation process later on.

4 These parameters include the state of intra-country construction manufacturing vintage of technology, geographical proximity to RSA, availability or lack of skilled construction sector manpower. There is likely to be some form simultaneity bias which is difficult to decipher exactly.

5 Thus the disturbances for this model take the following form where $\epsilon_{t}=\left(\epsilon_{i} t_{,} \in_{2} t, \ldots \ldots \in_{N}\right)$ is the vector of disturbances for project $i ; i$ $=1,2, \ldots, N)$ in period $t$. The covariance for two different construction project periods can be given as $E\left(\epsilon_{i} \epsilon_{s}^{t}\right)=\sigma_{i s} I_{N} \quad t, s=1,2, \ldots . T$. Note that $E\left(\epsilon_{i t} \epsilon_{i s}\right)$ is the covariance of each project $i$ over time while $E\left(\epsilon_{i t} \epsilon_{j s}\right)$ is the cross-sectional covariance which we assume to be zero.

6 Usually a robust test of the goodness of fit of the model would be to evaluate it empirically via a simulation exercise, i.e. use $t_{1}$ ex-post trends to carry out $t_{+1}$ ex-ante analysis. Alternatively it is possible to statistically validate an econometric model which has been estimated via maximum likelihood via the following procedure. The validation of the model herein followed the procedure in which the log-likelihood was evaluated at $L^{*}(0)=-512242$ with 183 degrees of freedom and fell to -366125 with the $\log$-likelihood evaluation as $L^{*}(\beta)$ with 141 degrees of freedom. The overall statistical validity of the model is fairly robust particularly given that the $\bar{\rho}_{2}$ value is 0.322 which falls within the acceptable range which Johnston (1984) has shown to be a good fit for model of this type. See Johnston J., Econometric Methods, McGraw Hill, 1984 for more on this. This validation procedure was used because firstly there are no previous empirical results and secondly there is no sufficiently clean data to test this model via simulation.

7 A good way of basically explaining the maximum-likelihood estimation method used herein is to assume a bounded random variable $p$ with a parameter with an unknown value since it is drawn from a random sample with data values of $y_{1}=1, y_{2}=1$ and $y_{3}=0$. 'The maximum-likelihood technique will choose the value of the unknown parameter $p$ that maximises the probability (likelihood) of randomly drawing the sample 
that was actually obtained.' Judge Hill, Griffiths, Lutkepohl, and Lee (1988), page 63. Since it is probabilistic the model is multiplicative.

8 In the tests for $t$ value significance one sided alternative hypothesis is used by using the critical value of $t$ (since it is usual to test at the $95 \%$ level of confidence). The $t(00)$ value cutting off $5 \%$ of the highest values in this data distribution is 1.645 and that cutting off the lowest values is -1.645 .

9 The current economic growth rate suggests that excess supply capacity exists in RSA industry (not just in the construction sector but through out the economy) which can easily be geared up to meet the demand pull impact of the RDP. Furthermore, stagflation (inflation and recession) is more likely than inflation on its own.

\section{REFERENCES}

1 COATES D. \& HILLARD J. (1987) The Economic Revival of Modern Britain - the Debate Between Left and Right, Edward Elgar Publishers.

2 EASTERLEY W. \& P. VIERRA da CUNHA (1994) "Financing the Storm: Macroeconomic Crises in Russia", Economics of Transition 2,4, 443-465.

3 FELLOWS R. \& LANGFORD D. (1993) Marketing and the Construction Client, Chartered Institute of Building Publication, London.

4 FISHLOW A. (1995) "Inequality, Poverty and Growth: Where do we stand?" Proceedings of the Annual World Bank Conference on Development Economics. World Bank Publications: 25-39.

5 FORREST J. (1992) "Management Aspects of Strategic Partnerships", Journal of General Management, 17(4): 25-40.

6 GOUDEN S., MERRIFIELD A., AMOD S., and NKOSI J. (1996) "Regionalising the RDP - Creating a Common Economic Community for the Construction and Allied Industries in Southern Africa", RSA Public Works Department Publication.

7 JOHNSTON. (1984) Econometric Methods, McGraw-Hill Publishers.

8 JUDGE G.E., CARTER HILL R., GRIFFITHS W. E., LUTKEPOHL H., and LEE T-C. Introduction to the Theory and Practice of Econometrics, John Wiley Publishers, $2^{\text {nd }}$ ed.

9 OKEAHALAM C.C. (1996) "An Analysis of the Expected Total Demand and Supply Capacity of South African Suppliers of Construction Materials", Report submitted to the RSA Public Works Department as part of the Enabling Environment Initiative Project.

10 PUBLIC WORKS DEPARTMENT, Republic of South Africa (1997) "Creating an Enabling Environment for Reconstruction, Growth and Development in the Construction Industry". 
11 SOUTHERN AFRICAN RESEARCH STRATEGY CONSULTING UNIT (SARCSC U)(1995) The Market for Building Materials.

12 TANZI V. (1996) "Fiscal Federalism and Decentralization: A Review of Some Efficiency and Macroeconomic Aspects", In Proceedings of the $8^{\text {th }}$ Annual World Bank Conference on Development Economics Bruno M and Pleskovic B, ed., World Bank Publication.

\section{ACKNOWLEDGEMENTS}

Some of the ideas for this paper originated from work which was carried out for the Ministry of Public Works of the Republic of South Africa in preparation for a Green Paper. I wish to acknowledge the comments of Sam Amod. The usual disclaimer applies. 